\title{
Readiness for Practice: A Survey of Neurosurgery Graduates and Program Directors
}

\author{
Faizal A. Haji, David A. Steven
}

\begin{abstract}
Background: Postgraduate neurosurgical education is undergoing significant reform, including transition to a competency-based training model. To support these efforts, the purpose of this study was to determine neurosurgical graduates' and program directors' (PDs) opinions about graduates' level of competence in reference to the 2010 Royal College Objectives of Training in Neurosurgery. Methods: An electronic survey was distributed to Canadian neurosurgery PDs and graduates from 2011. The questionnaire addressed graduates' abilities in nonprocedural knowledge and skills, CanMEDS roles, proficiency with core neurosurgical procedures and knowledge of complex neurosurgical techniques. Results: Thirteen of $22(59 \%)$ graduate and 17/25 (65\%) PD surveys were completed. There were no significant differences between PD and graduate responses. Most respondents agreed that these graduates possess the knowledge and skills expected of an independently practicing neurosurgeon across current objectives of training. A small proportion felt some graduates did not achieve this level of proficiency on specific vascular, functional, peripheral nerve and endoscopic procedures. This was partially attributed to limited exposure to these procedures during training and perceptions that some techniques required fellowshiplevel training. Conclusions: Graduating neurosurgical residents are perceived to possess a high level of proficiency in the majority of neurosurgical practice domains. Inadequate exposure during training or a perception that subspecialists should perform some procedures may contribute to cases where proficiency is not as high. The trends identified in this study could be monitored on an ongoing basis to provide supplemental data to guide curricular decisions in Canadian neurosurgical training.
\end{abstract}

RÉSUMÉ: Préparation à la pratique: enquête auprès des nouveaux diplômés et des directeurs de programme. Contexte: La formation postgraduée en neurochirurgie subit actuellement des réformes importantes dont la transition à un modèle de formation axée sur les compétences. Afin de soutenir ces efforts, cette étude a recueilli l'opinion des nouveaux gradués en neurochirurgie et des directeurs de programme (DP) sur le niveau de compétence des gradués par rapport aux objectifs de formation en neurochirurgie du Collège Royal émises en 2010. Méthode: Nous avons procédé à une enquête par voie électronique auprès de DP de neurochirurgie canadiens et des gradués du programme en 2011. Le questionnaire portait sur les habiletés des gradués en termes de connaissances et de compétences non procédurales, les rôles CanMeds, la compétence dans les techniques neurochirurgicales de base et la connaissance de techniques neurochirurgicales complexes. Résultats: Treize des 22 nouveaux gradués (59\%) et 17 des 25 DP (65\%) ont complété l'enquête. Il n'y avait pas de différence significative entre les réponses des DP et celles des nouveaux gradués. La plupart des répondants s'accordaient pour dire que ces nouveaux gradués possédaient les connaissances et les compétences attendues d'un neurochirurgien en pratique indépendante concernant la gamme des objectifs actuels de la formation. Un petit nombre estimait que certains nouveaux gradués n'avaient pas atteint ce niveau de compétence en ce qui a trait à certaines procédures vasculaires, fonctionnelles, endoscopiques ou nerveuses. Ceci était attribué partiellement à une exposition limitée à ces procédures pendant la formation et à la perception que certaines techniques demandent une formation complémentaire (fellowship). Conclusions: Les résidents en neurochirurgie qui finissent leur formation possèdent un haut niveau de compétence dans la majorité des domaines de pratique en neurochirurgie. Une exposition inadéquate pendant la formation ou une perception que des surspécialistes devraient effectuer certaines procédures peut contribuer à un moindre degré de compétence dans certains cas. Les tendances identifiées dans cette étude pourraient faire l'objet d'une surveillance continue afin de fournir des données additionnelles pour guider les décisions prises au sujet du curriculum de la formation en neurochirurgie au Canada.

Keywords: Neurosurgery residency, training objectives, national survey

doi:10.1017/cjn.2014.103

Can J Neurol Sci. 2014; 41: 721-728

In recent years, the climate of postgraduate neurosurgical training has undergone dramatic changes. Opportunities for direct neurosurgical instruction have been affected by duty-hour restrictions, increased emphasis on patient safety, rapid adoption of sophisticated neurosurgical techniques and resource constraints propagating the need to improve the efficiency of neurosurgical care. ${ }^{1-3}$ As a result, residents must acquire requisite knowledge and skills in less time and in more complex environments than ever before. Many choose to engage in at least one, if not multiple, additional years of fellowship training to gain the necessary technical skill to be 'experts' in their chosen subspecialty. 2,4

From the Department of Clinical Neurological Sciences (FAH, DAS) and Department of Epidemiology and Biostatistics (DAS), Western University, London, Ontario, Canada. Received July 23, 2014. Final Revisions Submitted October 8, 2014.

Correspondence to: David A. Steven, London Health Sciences Centre, University Hospital, Room A10-323, 339 Windermere Road, London, Ontario, Canada N6A 5A5. Email: david.steven@uwo.ca 
In turn, this raises important questions regarding what competencies fall within the purview of 'general' versus 'subspecialty' neurosurgical practice. ${ }^{5}$

This changing climate has not gone unnoticed by neurosurgical educators in Canada. In 2010, the Royal College of Physicians and Surgeons of Canada's (RCPSC's) Specialty Committee for Neurosurgery revised the specialty training requirements and objectives of training. Among the changes were an increase in 'on-service' training time from 36 to 42 months and the specification of procedural skills that graduating residents are expected to be proficient in performing, versus those they should be able to describe in detail but not necessarily perform. ${ }^{6}$ Recently, as part of the RCPSC competence by design initiative ${ }^{7}$ and the broader competency-based medical education (CBME) movement, ${ }^{4,8}$ neurosurgical educators have also been tasked with developing milestones ${ }^{9,10}$ to detail the abilities expected of neurosurgical trainees 'across the continuum of their careers, from the start of residency training and throughout professional practice'. ${ }^{11}$

Despite these broad changes to postgraduate neurosurgical education, there is relatively little literature to guide curricular reform. For instance, it may be helpful for neurosurgical educators to understand trainee and faculty perspectives on graduates' readiness for independent practice as they begin to delineate the level of competence (i.e. the level of ability or performance ${ }^{8}$ ) expected of neurosurgical trainees through CBME milestones. This report outlines the findings of a national survey of Canadian neurosurgical program directors (PDs) and graduate residents from 2011 conducted by the authors, with the support of the RCPSC Specialty Committee for Neurosurgery. The survey examined participants' perspectives on whether these graduates had achieved a level of proficiency expected of an independently practicing neurosurgeon among domains contained in the 2010 objectives for training as a marker of their perceived readiness for independent practice across various domains of neurosurgical practice.

\section{MeTHODS}

This cohort study used survey methodology and was conducted between October 2011 and August 2012.

\section{Participants and Data Collection}

Ethical approval was obtained from the University of Western Ontario Health Sciences Research Ethics Board. Administrators and PDs from each of the 14 Canadian neurosurgery training programs were contacted to generate a list of graduates in June 2011, resulting in 25 graduates across 11 programs. Each of these graduates completed training before the institution of the 2010 Objectives for Training. Because contact information was available for 22 graduates only, these individuals and the corresponding 11 PDs were invited to participate in the study. PDs were asked to complete one survey for each graduate of their program. Participants were emailed a letter of information and a unique, anonymized survey link. Informed consent was assumed from those who completed the questionnaire. Biweekly reminders were sent to nonresponders for the duration of the study.

\section{Survey Design}

Two structured, self-administered online questionnaires were developed for graduates and PDs, respectively (Appendix 1).
In both surveys, participants provided basic demographic information, then rated whether the graduate in question possessed the knowledge and skills expected of an independently practicing neurosurgeon on items pertaining to the 2010 RCPSC Objectives for Training in neurosurgery. ${ }^{6}$ These items were separated into four domains: (1) nonprocedural knowledge and skills (8 items); (2) the ability to independently perform general neurosurgical procedures (43 items); (3) knowledge regarding the indications, complications, nature and purpose of subspecialized neurosurgical procedures (26 items); and (4) nonmedical expert CanMEDS competencies (6 items). To reduce the length of the survey, a single survey item asked participants their opinion regarding graduates abilities on each of the nonmedical expert CanMEDS competencies (e.g. communicator, collaborator). Responses were scored on a five-point Likert scale ranging from one (strongly disagree) to five (strongly agree). Finally, open-ended questions were used to solicit participants' opinions on factors that may have prevented the graduate from achieving the expected level of competence on any of the items.

\section{Data Analysis}

Statistical analyses were completed using SPSS, version 21 (IBM Corp, Armonk, NY). Demographic characteristics were summarized using means for continuous variables and proportions for dichotomous variables. Likert responses were treated as ordinal data and summarized using median and range of responses. However, the Mann-Whitney test was used to determine if differences between graduate and PD responses were statistically significant with the Bonferroni correction to adjust for multiple comparisons. In addition, the proportions of respondents agreeing (three, four or five on the Likert scale) and disagreeing (one or two on the Likert scale) on each item were calculated. Finally, responses to open-ended questions were summarized based on predominant themes identified by the authors.

\section{ReSUlts}

\section{Response Rate and Demographics}

Of 47 questionnaires distributed, 30 responses were received (overall response rate, 64\%). Thirteen graduates completed the survey $(59 \%)$, two graduates declined to participate and the remaining seven did not respond. Seven PDs (64\%) completed 17 surveys (68\% of PD surveys), with no responses from the remaining four PDs. Most graduate nonresponders were from Ontario; however, PD nonresponders did not fit a specific pattern (each was from programs varying in size and geographic region).

Participant demographics are summarized in Table 1. Most resident respondents were graduates of Canadian medical schools and nearly half completed a graduate degree or infolded clinical fellowship during residency. PDs had an average of 3.4 (range, 0-6) years' experience leading the training program, with a mean of 5.3 graduates completing residency during this time. The number of responses by program is depicted in Figure 1, demonstrating the distribution of small, medium and large programs in the sample.

\section{Perceptions Regarding Graduates' Knowledge and Skills}

No significant differences between the mean ranks of PD and graduate responses were observed $(p>0.05$ in all cases after 
Table 1: Participant and program demographic characteristics

\begin{tabular}{|c|c|c|c|}
\hline Variable & $\mathbf{N}$ (range) & $\%$ & Comment \\
\hline \multicolumn{4}{|l|}{ A. Participant characteristics } \\
\hline \multicolumn{4}{|l|}{ Graduates } \\
\hline \multicolumn{4}{|l|}{ Responded to survey } \\
\hline Yes & 13 & 59 & \\
\hline No & 9 & 41 & 2 declined to participate, 7 did not respond \\
\hline \multicolumn{4}{|l|}{ Gender } \\
\hline Male & 12 & 92 & \\
\hline Female & 1 & 7 & \\
\hline Mean age at start of residency & $28.1(26-36)$ & - & \\
\hline Mean years in residency & $6.8(6-10)$ & - & \\
\hline \multicolumn{4}{|l|}{ Medical school } \\
\hline CMG & 10 & 77 & \\
\hline IMG & 3 & 23 & \\
\hline \multicolumn{4}{|l|}{ Prior residency training } \\
\hline Yes & 1 & 7 & 2 years of neurosurgery training \\
\hline No & 12 & 92 & \\
\hline \multicolumn{4}{|c|}{ Graduate degree or infolded fellowship during residency } \\
\hline Yes & 6 & 46 & 2 doctorates, 2 masters, 2 spine fellowships \\
\hline No & 7 & 54 & \\
\hline \multicolumn{4}{|l|}{$P D s^{*}$} \\
\hline \multicolumn{4}{|l|}{ Responded to survey } \\
\hline Yes & 7 & 64 & \\
\hline No & 4 & 36 & 4 no response \\
\hline Mean years as PD & $3.4(0-6)$ & - & \\
\hline Number of trainees graduated while a PD & $5.3(3-10)$ & - & \\
\hline \multicolumn{4}{|l|}{ B. Program characteristics } \\
\hline Number of residents & $13(5-35)$ & - & \\
\hline Number of fellows & $3.6(0-15)$ & - & \\
\hline Number of nurse practitioners & $3.4(0-12)$ & - & \\
\hline Number of attending surgeons & $13.1(5-29)$ & - & \\
\hline Annual caseload & $2357(600-6000)$ & - & \\
\hline
\end{tabular}

$\mathrm{CMG}=$ Canadian Medical Graduate; $\mathrm{IMG}=$ International Medical Graduate; $\mathrm{PD}=$ program director.

*3 programs did not have any graduates in 2011 and thus were not included in the study.

correcting for multiple comparisons). Both groups perceived that the vast majority of graduates from this cohort met all objectives related to nonprocedural knowledge and skills and CanMEDS competencies to the level expected of an independently practicing neurosurgeon (Table 2).

Almost all participants perceived that graduates in this cohort could perform the expected cranial and spinal procedures independently (Table 3). Similarly, with respect to oncological, vascular, pediatric, functional and peripheral nerve procedures, fewer than $15 \%$ of graduates were perceived to not be able to perform a selection of these procedures independently. Interestingly, with respect to craniotomy for repair of cerebral aneurysms, PDs indicated that $4 / 17$ graduates $(24 \%)$ would not be able to perform this procedure independently.
Although the majority of graduates were perceived to possess the level of knowledge expected of an independently practicing surgeon for subspecialty procedural skills listed (Table 4), between one and six graduates were not felt to have achieved this level. This was particularly the case for complex vascular procedures (e.g. extracranial/intracranial bypass), specialized techniques (e.g. stereotactic and functional procedures, stereotactic radiosurgery, endovascular embolization/stenting), uncommon spinal procedures (e.g. transoral spinal decompression) and complex peripheral nerve cases (e.g. surgical management of brachial plexus lesions, complex nerve tumours and sympathectomy).

PD and graduate responses to open-ended questions were concordant and thus were analyzed as a single group. The most commonly cited reasons for a graduate not being able to 


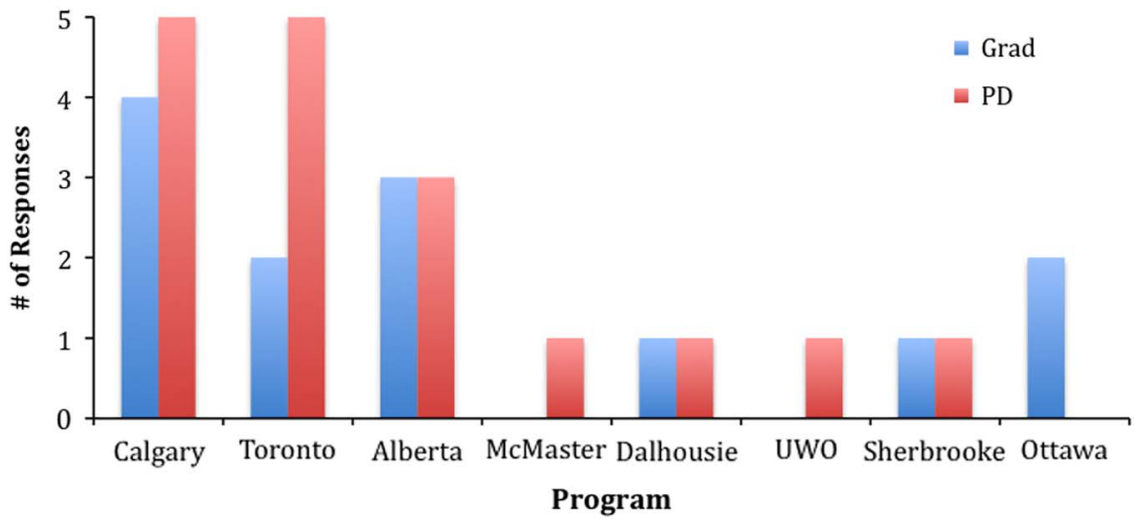

Figure 1: Distribution of graduate and program director responses by neurosurgical program.

independently perform or having limited knowledge of a given procedural skill were: (1) lack of exposure during training related to an inadequate caseload (e.g. percutaneous treatment of trigeminal neuralgia, endoscopy, complex vascular and peripheral nerve surgery), (2) lack of a formalized program for the subspecialty performing the procedure (e.g. functional neurosurgery) at the graduates' training centre or (3) a reluctance to involve residents in specific complex cases (e.g. endovascular or complex endonasal procedures). Some graduates indicated that they were receiving additional exposure to some of these techniques (e.g. endoscopy) during fellowship training. Several participants also indicated that although there was sufficient exposure to cases during residency, because some graduates would not be performing certain procedures (e.g. cranial-cervical instrumentation, craniotomy for cerebral aneurysm clipping, pediatric neurosurgical procedures) routinely in their practice, they would not feel comfortable performing these independently. These respondents felt such procedures should be performed by subspecialized surgeons with fellowship training.

\section{Discussion}

First introduced by Halstead in $1889,{ }^{4}$ a fundamental assumption of the traditional model of postgraduate surgical

Table 2: Perspectives on nonprocedural knowledge and CanMEDS competencies

\begin{tabular}{|c|c|c|c|c|}
\hline \multirow[t]{2}{*}{ Objective } & \multicolumn{2}{|c|}{ Graduate response } & \multicolumn{2}{|c|}{ PD response } \\
\hline & Median (range)* & Respondent agreement $^{\dagger}$ & Median (range)* & Respondent agreement $\dagger$ \\
\hline \multicolumn{5}{|l|}{ Nonprocedural knowledge and skills } \\
\hline Perform a neurosurgical consultation & $5(4-5)$ & $13(100 \%)$ & $5(4-5)$ & $17(100 \%)$ \\
\hline Identify and respond to ethical issues & $5(4-5)$ & $13(100 \%)$ & $5(4-5)$ & $17(100 \%)$ \\
\hline Prioritize professional responsibilities & $5(4-5)$ & $13(100 \%)$ & $5(4-5)$ & $17(100 \%)$ \\
\hline Demonstrate compassionate and patient-centred care & $5(4-5)$ & $13(100 \%)$ & $5(4-5)$ & $17(100 \%)$ \\
\hline Clinical/biomedical/socio-behavioural knowledge & $4(4-5)$ & $13(100 \%)$ & $4(3-5)$ & $17(100 \%)$ \\
\hline Pathology (gross and microscopic) & $4(3-5)$ & $13(100 \%)$ & $4(3-5)$ & $17(100 \%)$ \\
\hline Anatomy, physiology and embryology of the CNS & $5(4-5)$ & $13(100 \%)$ & $4(2-5)$ & $16(94 \%)$ \\
\hline Interpretation of diagnostic tests & $5(4-5)$ & $13(100 \%)$ & $5(3-5)$ & $17(100 \%)$ \\
\hline \multicolumn{5}{|l|}{ CanMEDS roles } \\
\hline Communicator & $5(4-5)$ & $13(100 \%)$ & $5(4-5)$ & $17(100 \%)$ \\
\hline Collaborator & $5(4-5)$ & $13(100 \%)$ & $5(4-5)$ & $17(100 \%)$ \\
\hline Manager & $5(2-5)$ & $12(92 \%)$ & $5(2-5)$ & $16(94 \%)$ \\
\hline Health advocate & $5(3-5)$ & $13(100 \%)$ & $5(4-5)$ & $17(100 \%)$ \\
\hline Scholar & $5(4-5)$ & $13(100 \%)$ & $5(3-5)$ & $17(100 \%)$ \\
\hline Professional & $5(4-5)$ & $13(100 \%)$ & $5(3-5)$ & $17(100 \%)$ \\
\hline
\end{tabular}

$\mathrm{CNS}=$ central nervous system; $\mathrm{PD}=$ program director.

*Median and range of responses on a 5 point Likert scale, from $1=$ strongly disagree to $5=$ strongly agree.

${ }^{\dagger}$ Indicates number of respondents who agree that the graduate in question achieved competence on the objective at the level of an independently practicing neurosurgeon (i.e. who provided a rating of 3,4 or 5 on the Likert scale, indicating neutral, agree or strongly agree). 
Table 3: Perspectives on ability to independently perform core neurosurgical procedures

\begin{tabular}{|c|c|c|c|c|}
\hline \multirow[t]{2}{*}{ Objective } & \multicolumn{2}{|c|}{ Graduate response } & \multicolumn{2}{|c|}{ PD response } \\
\hline & Median (range)* & Respondent agreement $^{\dagger}$ & Median (range)* & Respondent agreement $^{\dagger}$ \\
\hline \multicolumn{5}{|l|}{ Cranial procedures: } \\
\hline Burrholes for biopsy & $5(4-5)$ & $13(100 \%)$ & $5(4-5)$ & $17(100 \%)$ \\
\hline Burrholes for hematoma & $5(4-5)$ & $13(100 \%)$ & $5(4-5)$ & $17(100 \%)$ \\
\hline Burrholes for ICP monitoring & $5(4-5)$ & $13(100 \%)$ & $5(4-5)$ & $17(100 \%)$ \\
\hline Craniotomy for hematoma & $5(4-5)$ & $13(100 \%)$ & $5(4-5)$ & $17(100 \%)$ \\
\hline Craniotomy for infection & $5(4-5)$ & $13(100 \%)$ & $5(4-5)$ & $17(100 \%)$ \\
\hline Craniotomy for biopsy & $5(4-5)$ & $13(100 \%)$ & $5(4-5)$ & $17(100 \%)$ \\
\hline Decompressive craniectomy & $5(4-5)$ & $13(100 \%)$ & $5(4-5)$ & $17(100 \%)$ \\
\hline Use of image guidance & $5(4-5)$ & $13(100 \%)$ & $5(4-5)$ & $17(100 \%)$ \\
\hline Treatment of simple and compound skull fractures & $5(3-5)$ & $13(100 \%)$ & $5(4-5)$ & $17(100 \%)$ \\
\hline Cranioplasty & $5(3-5)$ & $13(100 \%)$ & $5(4-5)$ & $17(100 \%)$ \\
\hline External ventricular drainage & $5(4-5)$ & $13(100 \%)$ & $5(4-5)$ & $17(100 \%)$ \\
\hline Endoscopic third ventriculostomy & $5(4-5)$ & $13(100 \%)$ & $5(4-5)$ & $17(100 \%)$ \\
\hline Ventricular shunt & $5(4-5)$ & $13(100 \%)$ & $5(4-5)$ & $17(100 \%)$ \\
\hline Ventricular cyst or access device insertion & $5(4-5)$ & $13(100 \%)$ & $5(4-5)$ & $17(100 \%)$ \\
\hline \multicolumn{5}{|l|}{ Spinal procedures: } \\
\hline Anterior cervical discectomy & $5(4-5)$ & $13(100 \%)$ & $5(4-5)$ & $17(100 \%)$ \\
\hline Anterior vertebrectomy & $5(4-5)$ & $13(100 \%)$ & $5(3-5)$ & $17(100 \%)$ \\
\hline Posterior cervical laminectomy/foraminotomy & $5(4-5)$ & $13(100 \%)$ & $5(3-5)$ & $17(100 \%)$ \\
\hline Posterior thoracic laminectomy & $5(4-5)$ & $13(100 \%)$ & $5(4-5)$ & $17(100 \%)$ \\
\hline Posterolateral thoracic decompression & $4(2-5)$ & $12(92 \%)$ & $4(3-5)$ & $17(100 \%)$ \\
\hline Posterior lumbar laminectomy & $5(4-5)$ & $13(100 \%)$ & $5(4-5)$ & $17(100 \%)$ \\
\hline Posterior lumbar discectomy & $5(4-5)$ & $13(100 \%)$ & $5(4-5)$ & $17(100 \%)$ \\
\hline Posterolateral lumbar decompression & $4(2-5)$ & $12(92 \%)$ & $4(4-5)$ & $17(100 \%)$ \\
\hline Anterior cervical arthrodesis & $5(4-5)$ & $13(100)$ & $5(4-5)$ & $17(100 \%)$ \\
\hline Posterior cranial-cervical arthrodesis $(\mathrm{O} / \mathrm{C} 1 / \mathrm{C} 2)$ & $3(2-5)$ & $12(92 \%)$ & $3(3-5)$ & $17(100 \%)$ \\
\hline Posterior subaxial cervical arthrodesis & $5(2-5)$ & $12(92 \%)$ & $4(3-5)$ & $17(100 \%)$ \\
\hline Posterior thoracolumbar arthrodesis & $4(2-5)$ & $12(92 \%)$ & $4(3-5)$ & $17(100 \%)$ \\
\hline Posterior lumbar arthrodesis & $4(3-5)$ & $13(100 \%)$ & $4(3-5)$ & $17(100 \%)$ \\
\hline Closed reduction/immobilization of cervical fractures & $5(4-5)$ & $13(100 \%)$ & $5(3-5)$ & $17(100 \%)$ \\
\hline Resection of intradural extramedullary spinal tumours & $4(4-5)$ & $13(100 \%)$ & $4(4-5)$ & $17(100 \%)$ \\
\hline Spinal CSF diversion/shunt & $4(2-5)$ & $12(92 \%)$ & $5(4-5)$ & $17(100 \%)$ \\
\hline CSF Leak Repair & $4(3-5)$ & $13(100 \%)$ & $4(4-5)$ & $17(100 \%)$ \\
\hline \multicolumn{5}{|c|}{ Oncological, vascular, pediatric, functional and peripheral nerve procedures: } \\
\hline Craniotomy for resection of intrinsic/extrinsic tumors & $5(4-5)$ & $13(100 \%)$ & $5(4-5)$ & $17(100 \%)$ \\
\hline Transsphenoidal removal of pituitary tumours & $4(2-5)$ & $12(92 \%)$ & $4(2-5)$ & $16(94 \%)$ \\
\hline Ventricular endoscopy for tumour biopsy or excision & $4(2-5)$ & $11(85 \%)$ & $4(3-5)$ & $17(100 \%)$ \\
\hline Craniotomy for repair of cerebral aneurysms & $4(2-5)$ & $12(92 \%)$ & $4(2-5)$ & $13(76 \%)$ \\
\hline Extracranial cerebrovascular procedures (carotid endarterectomy) & $4(3-5)$ & $13(100 \%)$ & $4(2-5)$ & $16(94 \%)$ \\
\hline Release of tethered cord & $5(2-5)$ & $12(92 \%)$ & $4(3-5)$ & $17(100 \%)$ \\
\hline Treatment of simple sagittal craniosynostosis & $4(1-5)$ & $12(92 \%)$ & $4(3-5)$ & $17(100 \%)$ \\
\hline Fontanelle tap & $4(1-5)$ & $12(92 \%)$ & $4(3-5)$ & $17(100 \%)$ \\
\hline Skull tumour biopsy/resection & $5(3-5)$ & $13(100 \%)$ & $5(4-5)$ & $17(100 \%)$ \\
\hline Microvascular decompression & $4(4-5)$ & $13(100 \%)$ & $4(3-5)$ & $17(100 \%)$ \\
\hline Percutaneous techniques for trigeminal neuralgia & $4(2-5)$ & $12(92 \%)$ & $3(2-5)$ & $15(88 \%)$ \\
\hline
\end{tabular}


Table 3: Continued

\begin{tabular}{|c|c|c|c|c|}
\hline \multirow[t]{2}{*}{ Objective } & \multicolumn{2}{|c|}{ Graduate response } & \multicolumn{2}{|c|}{ PD response } \\
\hline & Median (range)* & Respondent agreement $^{\dagger}$ & Median (range)* & Respondent agreement ${ }^{\dagger}$ \\
\hline Carpal tunnel decompression & $5(3-5)$ & $13(100 \%)$ & $4(2-5)$ & $16(94 \%)$ \\
\hline Ulnar nerve decompression and transposition & $4(3-5)$ & $13(100 \%)$ & $4(2-5)$ & $16(94 \%)$ \\
\hline Nerve and muscle biopsy & $4(3-5)$ & $13(100 \%)$ & $4(3-5)$ & $17(100 \%)$ \\
\hline Sural nerve harvest & $4(2-5)$ & $12(92 \%)$ & $4(3-5)$ & $17(100 \%)$ \\
\hline Resection of simple nerve tumours & $4(3-5)$ & $13(100 \%)$ & $4(3-5)$ & $17(100 \%)$ \\
\hline \multicolumn{5}{|l|}{ Free text comments: } \\
\hline \multicolumn{5}{|c|}{$\begin{array}{l}\text { - I would not feel comfortable performing OC instrumentation independently, mostly because my interest is not in spine and my experience } \\
\text { during training was that these cases were performed by spine subspecialists. I was exposed to an adequate number of cases during my } \\
\text { residency; however, I believe that if there are subspecialists, they should be the ones doing it. } \\
\text { - Limited endoscopic experience/expertise, no harvest of sural nerves for grafts in training. } \\
\text { - Not enough varied exposure/caseload of complex open aneurysm cases, not enough exposure/case load of trigeminal neuralgia cases. } \\
\text { - Overall exposure to pediatrics is low in most training programs - my practice has virtually none. } \\
\text { - Peripheral nerve cases-inadequate case load to feel completely comfortable; Aneurysms-I had moderate amount of exposure; however, } \\
\text { because I do not plan on doing vascular neurosurgery, I don't think I would be comfortable doing this independently. } \\
\text { - Endoscopy-not enough exposure on using the scopes independently as a resident. I am gaining experience in this area as a fellow. } \\
\text { - Transsphenoidal tumours-I would be comfortable doing this as a combined case with ENT doing an endoscopic endonasal approach. }\end{array}$} \\
\hline
\end{tabular}

$\mathrm{CSF}=$ cerebrospinal fluid; $\mathrm{ICP}=$ intracranial pressure; $\mathrm{OC}=$ Occipito-cervical; $\mathrm{PD}=$ program director.

*Median and range of responses on a 5 point Likert scale, from $1=$ strongly disagree to $5=$ strongly agree.

${ }^{\dagger}$ Indicates number of respondents who agree that the graduate in question achieved competence on the objective at the level of an independently practicing neurosurgeon (i.e. who provided a rating of 3,4 or 5 on the Likert scale, indicating neutral, agree, or strongly agree).

education is that the sheer volume of cases a trainee is exposed to will ensure mastery of expected competencies. ${ }^{12}$ However, given the time and resource constraints pervasive in today's surgical training climate, current residents are likely not exposed to the same volume and breadth of clinical experiences as residents from even a decade ago. Thus, it is not surprising that this model is being phased out in favour of CBME in an effort to foster outcome-driven curricula and assessments that build over time and focus on observable knowledge and skills. ${ }^{7,8}$ In turn, the operationalization of CBME through specialty-specific milestones ${ }^{9,11}$ and entrustable professional activities ${ }^{10,13}$ may provide faculty and trainees with a transparent pathway to the acquisition of competencies required for independent neurosurgical practice. $^{8,11}$ Because these milestones, entrustable professional activities and other curricular changes will be developed through expert consensus among neurosurgical educators, data on practice patterns, societal needs and competence of graduates in the various domains of neurosurgical practice may help advance these efforts.

The current study adds a small piece to this body of literature, providing new insight on the perceptions of Canadian neurosurgical graduates' abilities related to the current objectives of training. However, before interpreting the result, several important limitations should be considered. First, because these data pertain to a single graduating class, the results may not be generalizable to future cohorts or programs not represented in the study. Similarly, the potential for nonresponder bias must also be considered given the response rates of $59 \%$ and $68 \%$. Second, because of the small sample size, we are not able to comment on the impact of demographic characteristics (e.g. whether graduates completed medical school in Canada or abroad, the number of fellows in the training program) on the study findings. Third, because the questionnaire was not validated before use, participants may have misinterpreted some questions. In particular, participants may have interpreted items related to knowledge of subspecialty procedures as asking about graduates' ability to perform these techniques. Although we set this question apart on a separate page with distinct instructions from the preceding section on performing core procedural skills, we cannot be certain that the question was answered with our intent in mind. Finally, the self-report measures used in the study introduce the potential for recall bias and 'halo' effects. Because we do not have objective data from in-training reports, RCPSC certification examinations or practice performance data to corroborate the survey results, the study findings should be interpreted with due caution.

The language of the survey questions themselves must also be considered in interpreting the results. Participants were explicitly asked whether graduates were proficient at the level of an 'independently practicing neurosurgeon'. This differs from the expectations outlined in the RCPSC Objectives of Training, which state that trainees must 'demonstrate proficiency' in performing the procedural skills listed in Table 2 and for those listed in Table 3, be able to "describe the...procedural skills, along with... [their] indications..., ...nature and purpose..., and... potential complications". ${ }^{6}$ Some graduates may have reached 'proficiency' sufficient to meet a given objective (e.g. craniotomy for aneurysm repair), but not feel comfortable as a junior consultant to perform the surgery without a senior colleague. That multiple respondents indicated they believed some procedures should only be performed by subspecialists supports this notion. Thus, these results should not be interpreted to reflect graduate or PD opinions about whether training objectives were met per se, but rather whether graduates had reached an independent level of practice in these domains. This threshold for proficiency is likely 


\section{Table 4: Perspectives on knowledge of 'subspecialty' procedures}

\begin{tabular}{|c|c|c|c|c|}
\hline \multirow[t]{2}{*}{ Objective } & \multicolumn{2}{|c|}{ Graduate response } & \multicolumn{2}{|c|}{ PD response } \\
\hline & Median (range)* & Respondent agreement $^{\dagger}$ & Median (range)* & Respondent agreement \\
\hline Craniotomy for complex aneurysms & $4(1-5)$ & $12(92 \%)$ & $5(2-5)$ & $13(76 \%)$ \\
\hline Craniotomy for vascular malformations & $4(1-5)$ & $12(92 \%)$ & $5(2-5)$ & $13(76 \%)$ \\
\hline Craniotomy for EC/IC bypass & $4(1-5)$ & $8(62 \%)$ & $4(2-5)$ & $12(71 \%)$ \\
\hline Craniotomy for complex tumours & $4(2-5)$ & $12(92 \%)$ & $5(2-5)$ & $14(82 \%)$ \\
\hline Stereotactic and functional procedures & $4(1-4)$ & $11(85 \%)$ & $4(2-5)$ & $12(71 \%)$ \\
\hline Surgical treatment of epilepsy & $4(2-5)$ & $12(92 \%)$ & $5(2-5)$ & $13(76 \%)$ \\
\hline Expanded endonasal skull base approaches & $4(1-4)$ & $10(77 \%)$ & $3(2-5)$ & $13(76 \%)$ \\
\hline Stereotactic radiotherapy and radiosurgery & $4(1-5)$ & $11(85 \%)$ & $4(2-5)$ & $12(71 \%)$ \\
\hline Carotid stenting and endovascular embolization & $4(1-5)$ & $9(69 \%)$ & $4(2-5)$ & $11(65 \%)$ \\
\hline Transoral spinal decompression & $4(1-5)$ & $11(85 \%)$ & $4(2-5)$ & $12(71 \%)$ \\
\hline Thoracic anterior transcavitary spinal decompression & $4(2-5)$ & $12(92 \%)$ & $4(2-5)$ & $13(76 \%)$ \\
\hline Lumbosacral transabdominal/retroperitoneal decompression & $4(2-5)$ & $12(92 \%)$ & $4(2-5)$ & $13(76 \%)$ \\
\hline Odontoid screw fixation & $5(1-5)$ & $12(92 \%)$ & $4(2-5)$ & $15(88 \%)$ \\
\hline $\mathrm{C} 1 / \mathrm{C} 2$ fixation & $4(1-5)$ & $11(85 \%)$ & $4(2-5)$ & $16(94 \%)$ \\
\hline Multilevel complex spinal reconstruction/ arthrodesis & $4(2-5)$ & $11(85 \%)$ & $4(2-5)$ & $16(94 \%)$ \\
\hline Cervical-thoracic arthrodesis & $4(2-5)$ & $11(85 \%)$ & $4(2-5)$ & $16(94 \%)$ \\
\hline Thoracic arthrodesis $( \pm$ instrumentation $)$ & $4(2-5)$ & $12(92 \%)$ & $4(2-5)$ & $15(88 \%)$ \\
\hline Vertebroplasty/ kyphoplasty & $4(1-5)$ & $12(92 \%)$ & $4(2-5)$ & $13(76 \%)$ \\
\hline Laminoplasty & $5(4-5)$ & $13(100 \%)$ & $5(4-5)$ & $17(100 \%)$ \\
\hline Surgical management of cord tumours/vascular malformations & $4(4-5)$ & $13(100 \%)$ & $4(3-5)$ & $17(100 \%)$ \\
\hline Surgical management of complex dysraphism & $4(2-5)$ & $12(92 \%)$ & $4(2-5)$ & $13(76 \%)$ \\
\hline Surgical management of brachial plexus lesions & $4(1-4)$ & $11(85 \%)$ & $5(1-5)$ & $12(71 \%)$ \\
\hline Nerve grafting & $4(1-5)$ & $11(85 \%)$ & $5(2-5)$ & $13(76 \%)$ \\
\hline Surgery for entrapment neuropathy (non-CTS/ulnar nerve) & $4(1-5)$ & $12(92 \%)$ & $4(2-5)$ & $13(76 \%)$ \\
\hline Surgical management of complex nerve tumours & $4(1-4)$ & $12(92 \%)$ & $4(2-5)$ & $11(65 \%)$ \\
\hline Sympathectomy & $3(1-4)$ & $9(69 \%)$ & $4(1-5)$ & $12(71 \%)$ \\
\hline
\end{tabular}

Free text comments:

Either lack of an organized program (e.g. functional), or reluctance to involve residents in these procedures (i.e. endovascular, complex endonasal) [contributed to low ranking of these items].

- Mostly low scores do not relate to resident competence, merely lack of adequate cases during training.

$\mathrm{CTS}=$ cubital tunnel syndrome; $\mathrm{EC} / \mathrm{IC}=$ extracranial/intracranial $\mathrm{PD}=$ program director

*Median and range of responses on a 5 -point Likert scale, from $1=$ strongly disagree to $5=$ strongly agree.

${ }^{\dagger}$ Indicates number of respondents who agree that the graduate in question achieved competence on the objective at the level of an independently practicing neurosurgeon (i.e. who provided a rating of 3,4 or 5 on the Likert scale, indicating neutral, agree or strongly agree).

too high for some of the objectives and not reflective of the expectations of neurosurgical graduates and may account for the lower ratings observed on some survey items. However, this distinction does raise an important issue: there is a need to clarify exactly what it means for a graduating neurosurgical resident to be 'proficient' within each domain described in the objectives. Such a clarification is beyond the scope of this article, but underscores the importance of developing training milestones ${ }^{9}$ and transparent definitions of the minimum competence standard expected of neurosurgical graduates for each training objective.

Notwithstanding these limitations, we believe the results of this study may be useful to inform neurosurgical curriculum design and assessment. For instance, that nearly half of graduates pursued a graduate degree or infolded fellowship during training may reflect a desire among residents to develop subspecialized academic and clinical skills not mandated by the existing training curriculum. This finding also demonstrates the freedom of trainees in Canadian neurosurgical programs to pursue individual educational objectives. The results also paint a positive picture for the calibre of neurosurgical training in Canada, given that graduates surveyed were perceived to be proficient to the level of an independently practicing neurosurgeon in the vast majority of objectives. This is particularly true for nonprocedural skills, CanMEDs competencies and performance of core neurosurgical procedures, perhaps with the exception of 'craniotomy for cerebral aneurysm clipping', 'ventricular endoscopy for tumour biopsy or excision' and 'percutaneous techniques 
for trigeminal neuralgia'. That the former two procedures were rated lower is of interest but not entirely surprising given the growing role of endovascular therapy and the relatively recent addition of ventricular endoscopy to the neurosurgical armamentarium. The perception that residents have inadequate exposure to feel comfortable performing these procedures independently and that these procedures should be performed by subspecialists underscores the importance of monitoring the adequacy of exposure and proficiency of graduating residents in these domains to inform curricular decisions both for individual programs and at the national level.

Although the majority of graduates were perceived to have a level of knowledge expected of an independently practicing neurosurgeon on the majority of subspecialized techniques, for some procedures (e.g. complex vascular, stereotactic, functional, peripheral nerve, radiosurgery, complex spine), a proportion of graduates may not receive sufficient exposure to these subspecialty cases to achieve this level of proficiency. This trend is once again not surprising given that fellowship-trained subspecialists almost exclusively perform these procedures and exposure to these cases depends on whether such services are offered at the centre in question; for some of these services (e.g. radiosurgery), patients may be sent to another centre when these interventions are indicated. In addition, at certain centers, some of these procedures (e.g. complex peripheral nerve surgery, endovascular interventions, some stereotactic and functional procedures) are not managed by the neurosurgical service, but rather by colleagues in other surgical specialties. However, because these are not procedures that graduates are expected to be able to perform, and because all Canadian medical residents must successfully complete the RCPSC certification examination (which thoroughly examines knowledge and decision-making in these domains), ratings on these objectives are arguably less critical for decision-making.

These results provide some insight into the perceived level of competence of graduating neurosurgical residents across the existing objectives of training. These data may be useful in future decisionmaking regarding competency milestones and training objectives as well as to articulate which of these fall within 'core' neurosurgical training and which should be considered subspecialty-level skills. Because of the aforementioned limitations of the data, it would be helpful to follow the trends observed in this study among future graduate cohorts to determine if the findings are isolated or if they represent the experience of Canadian neurosurgical trainees in general. In addition, because the graduates in this study completed training before the institution of the 2010 curricular reforms, it would be of interest to compare these results with trainees graduating after 2016 (who will complete 42 months 'on-service' during residency) or those who are trained under the CBME paradigm to determine if observed trends change with these curricular reforms. Additional data on graduates' level of proficiency, practice patterns and changing societal needs would also be helpful as objective evidence to corroborate these results. Thus, we would advocate for ongoing monitoring of this nature that PDs and the RCPSC specialty committee may draw upon in the future to inform curriculum decisions.

\section{CONCLUSIONS}

We have conducted a national survey of graduating neurosurgical residents and PDs, to determine graduates' preparedness for independent neurosurgical practice based on the RCPSC Objectives for Training. The results of the current study suggest that, in the majority of cases, PDs and graduates feel that this graduating cohort achieved a level of proficiency expected of an independently practicing neurosurgeon on the current list of objectives, despite the fact that these residents completed training before these objectives were incorporated into Canadian neurosurgical training curricula. Among the select number of cases in which this proficiency criterion was not met, inadequate exposure to certain procedures during training or a perception that such cases should be performed only by fellowship-trained surgeons may have been a contributing factor. The trends identified in this study should be monitored on an ongoing basis to provide much needed data to guide curricular decisions in Canadian neurosurgical training.

\section{ACKNOWLEDGEMENTS}

The authors sincerely thank the members of the Royal College Specialty Committee for Neurosurgery for their input and constructive feedback on this study.

\section{Disclosures}

FAH does not have anything to disclose.

\section{SUPPLEMENTARY MATERIAL}

To view supplementary material for this article, please visit http://dx.doi.org/10.1017/cjn.2014.103

\section{REFERENCES}

1. Jagannathan J, Vates GE, Pouratian N, et al. Impact of the Accreditation Council for Graduate Medical Education work-hour regulations on neurosurgical resident education and productivity. $\mathrm{J}$ Neurosurg. 2009;110(5):820-7.

2. Desbiens R, Elleker MG, Goldsand G, et al. Current educational issues in the clinical neurosciences. Can J Neurol Sci. 2001;28(4): 299-308.

3. Haji FA, Dubrowski A, Drake J, de Ribaupierre S. Needs assessment for simulation training in neuroendoscopy: a Canadian national survey. J Neurosurg. 2013;118(2):250-7.

4. Long DM. Competency-based residency training: the next advance in graduate medical education. Acad Med. 2000;75(12):1178-83.

5. Toyota BD. Spinal subspecialization in post-graduate neurosurgical education. Can J Neurol Sci. 2004;31(2):204-7.

6. Royal College of Physicians and Surgeons of Canada. Objectives of training in the specialty of neurosurgery. Available from: http:// www.royalcollege.ca/cs/groups/public/documents/document/y2vk/ mdaw/ edisp/tztest3rcpsced000920.pdf.

7. Royal College of Physicians and Surgeons of Canada. Competence by design (CBD): moving towards competency-based medical education. Available from: http://www.royalcollege.ca/portal/ page/portal/rc/resources/cbme.

8. Frank JR, Snell LS, Cate OT, et al. Competency-based medical education: theory to practice. Med Teach. 2010;32(8):638-45.

9. Green ML, Aagaard EM, Caverzagie KJ, et al. Charting the road to competence: developmental milestones for internal medicine residency training. J Grad Med Educ. 2009;1(1):5-20.

10. Peterson SJ, Nabors C, Frishman WH. Milestones: direct observation may be the key to accelerated training. Am J Med. 2013;126(12): $1031-2$

11. Royal College of Physicians and Surgeons of Canada. Specialtyspecific milestones provide clear and transparent learning path. Available from: http://www.royalcollege.ca/portal/page/portal/rc/ resources/publications/oe_news/vol4_2/ss_milestones.

12. Reznick RK, MacRae H. Teaching surgical skills-changes in the wind. N Engl J Med. 2006;355(25):2664-9.

13. ten Cate O, Scheele F. Competency-based postgraduate training: can we bridge the gap between theory and clinical practice? Acad Med. 2007;82(6):542-7. 